Nadira A Hatim

BDS, MSc (Assist Prof)

Balsam K. Fathi

BDS, HD (Prosthodontist)

\section{Gag Reflex Reduction in A Patient with Maxillofacial Prosthesis. ( A Clinical Report )}

\begin{abstract}
Aim: the study was dedicated to demonstrate the importance of binding the old concepts of preventing the gag reflex during the prosthodontic work together with the new advance in the concepts, techniques, and materials in this scope. Materials and Methods: Silicone rubber base impression material (Oranwash L, Zhermack, Italy) light, and heavy body was used in the study to take the impression by a new technique (cheek bite technique) without the use of a tray, and on incremental basis, which showed more comfort and better results. The prosthesis given to the patient took advantage of the neutral zone principles, which whenever applied it gives better results, it was hollowed, in addition, the procedure carried less stimulation to the gag reflex, and more assurance. Results: The obturator obtained by the technique described was larger in size, lighter in weight, and more comfortable, and efficient in function compared to the old one ,the entire procedure from the impression taking, to the delivery, and after, carried less stimulation of the gag reflex, and gave better results. Conclusion: The advance in the prosthetic materials, and techniques when combined with the available techniques, and information can give better results.
\end{abstract}

Key words: Obturator, Gag reflex, Maxillofacial.

Hatim NA, Fathi BK. Gag Reflex Reduction in A Patient with Maxillofacial Prosthesis. ( A Clinical Report ). Al-Rafidain Dent J. 2008; 8(1 ): 114-119.

Received: 23/5/2007 Sent to Referees: 23/5/2006

Accepted for Publication: 19/6/2007

\section{INTROUCTION}

The gag reflex is an involuntary contraction of the muscles of the soft palate, or the pharynx that result in retching. ${ }^{(1)}$ It is a basic physiologic mechanism, which safeguards the airways from foreign bodies ${ }^{(2,3)}$. In retching, peristalsis becomes spasmodic, uncoordinated, and the direction is reversed, air is forced over the closed glottis producing a characteristic retching sound, patient who gags, presents with a range of disruptive reactions from simple contraction of the palatal, or circum-oral musculature, to spasm of pharyngeal structure accompanied by vomiting ${ }^{(4,5,6,7)}$. This reflex is exaggerated in some individuals ${ }^{(3,8,9)}$, the exaggerated reflex often dissuade the patient from seeking regular oral care, as a consequence, the severely affected patient tends not to seek regular oral care presenting only when in pain, and may request treatment under general anesthesia ${ }^{(7)}$, providing dental treatment for such patient can be a harrowing procedure for all the concerned, the patient inevitably becomes distressed because of uncomfortable feeling of nausea , the dentist becomes irritated at not being able to provide high quality treatment, and the dental nurse has feeling of some impending doom -knowing who will have to clean the mess if the patient vomits ${ }^{(10)}$.

Gagging has been generally classified as either somatogenic, or psychogenic ${ }^{(8,11,12)}$.Psychogenic gagging is induced by anxiety ,fear, and apprehension ${ }^{(13)}$.all the possible causes must be investigated rather than placing the blame on the psychological make up of the patient ${ }^{(14)}$,gag reflexes that are hyperactive for whatever reason 
are not uncommon, and present a problem for the dentists ,particularly when it is necessary to make impression, or fit a prosthesis ${ }^{(15,16)}$, it is a serious problem because failure to overcome the hyperactive reflex may leave the patient permanently edentulous, an esthetically and nutritionally unsatisfactory outcome ${ }^{(15)}$. The aim of this study was to fabricate a maxillofacial prosthesis for a patient with a palatal defect, and a distinct gag reflex problem in such a way that he faced minimal gagging, and had more comfort during the construction, and after the placement of the prosthesis.

\section{MATERIALS AND METHODS}

A male patient, 39 years old presented with a large defect in soft, and hard palate, caused by an operation for excision of a malignant lesion in the area 8 years ago, the patient also had a slightly limited mouth opening, multiple carious teeth, extracted upper right first premolar, upper left first, and second premolars, and first, second, and third molars, fibrosis in the area of the excision, partially edentulous ridges and a distinct gag reflex [Figure 1(No.1)].

The patient had a previous visit to a dental clinic for the construction of a maxillofacial prosthesis 6 months after the operation where the complete healing in the operation site took place, the patient was provided with a prosthesis in which the part filling the defect was solid and much smaller than the defect size, the old obturator became unsatisfactory because of the multiple teeth extraction [Figure 1(No.2)]. This patient attended the dental clinic for maxillofacial appliance fabrication.

\section{Technique :}

The treatment planning consisted of scaling and polishing, conservative treatment of the carious teeth, and then, construction of prosthodontic appliance. The steps for the construction of the appliance included:
1. A psychological preparation of patient, in a sympathetic manner was used by the careful explanation of the treatment plan, and the impression taking procedure, the purpose of each step was illustrated to the patient to reduce the fear and anxiety $(17,18)$.

2. The patient was instructed to rinse his mouth thoroughly by tap water before the impression procedure was started (19).

3 . The dental chair was adjusted so that the patient sat in an upright position $(17,20)$.

4. As the patient had a gagging problem, the impression was taken using Zetaplus silicone rubber base impression material (Zhermack, Italy) (21) with an additional amount of accelerator to hasten the setting time (22).

5. No tray was used, and the first bulk of the heavy body impression material (which was supported by fingers until its set) was used as a tray to carry the second bulk of the heavy body, and the definitive wash of the light body material (Oranwash L, Zhermack, Italy). [Figure 1(No.3)].

6. The patient was instructed to swallow while the impression is being taken in an attempt to record the cut edges of the palate, and the adjacent areas in function, and to decrease the possibilities of over extension in these areas which cause discomfort and might initiate gagging.

7. The upper, and lower arch impressions were taken in the same step by asking the patient to bite after swallowing (Cheek bite impression technique).

8. The upper impression was casted first, then after it was completely set the lower impression on the opposite side was casted [Figure 1(No.3)].

9. After a complete set of the lower impression, the two casts were separated from their impressions, and a removable partial denture was constructed [Figure 1(No.4)], which had a very deep roof, and shorter posterior limit than that desired to fill the defect.

10. The removable partial denture was 
inserted in the patient mouth, and the flanges and occlusion were checked.

11. The removable partial denture was removed, and a piece of heavy body material with an additional amount of accelerator was added to the partial denture on the polished surface of the palate and the patient was asked to swallow so that the impression material was molded by the action of the tongue to the original height of the roof of the mouth [Figure 1(No.5)].

12. A thin layer of Vaseline was put on the impression after it was taken (by heavy body silicone rubber base material and the partial denture) (tissue side).

13. The impression was casted [Figure 1(No.6)], and a Vaseline layer was placed all over the tissue surface of the cast.

14. A sheet of base plate wax was melted, and placed in the cavity created by the impression on the cast to the level created by the impression.

15. The wax after it hardened was removed, and placed in the denture, sealed temporarily by wax drops, and checked inside the patient mouth [Figure 1(No.7)].
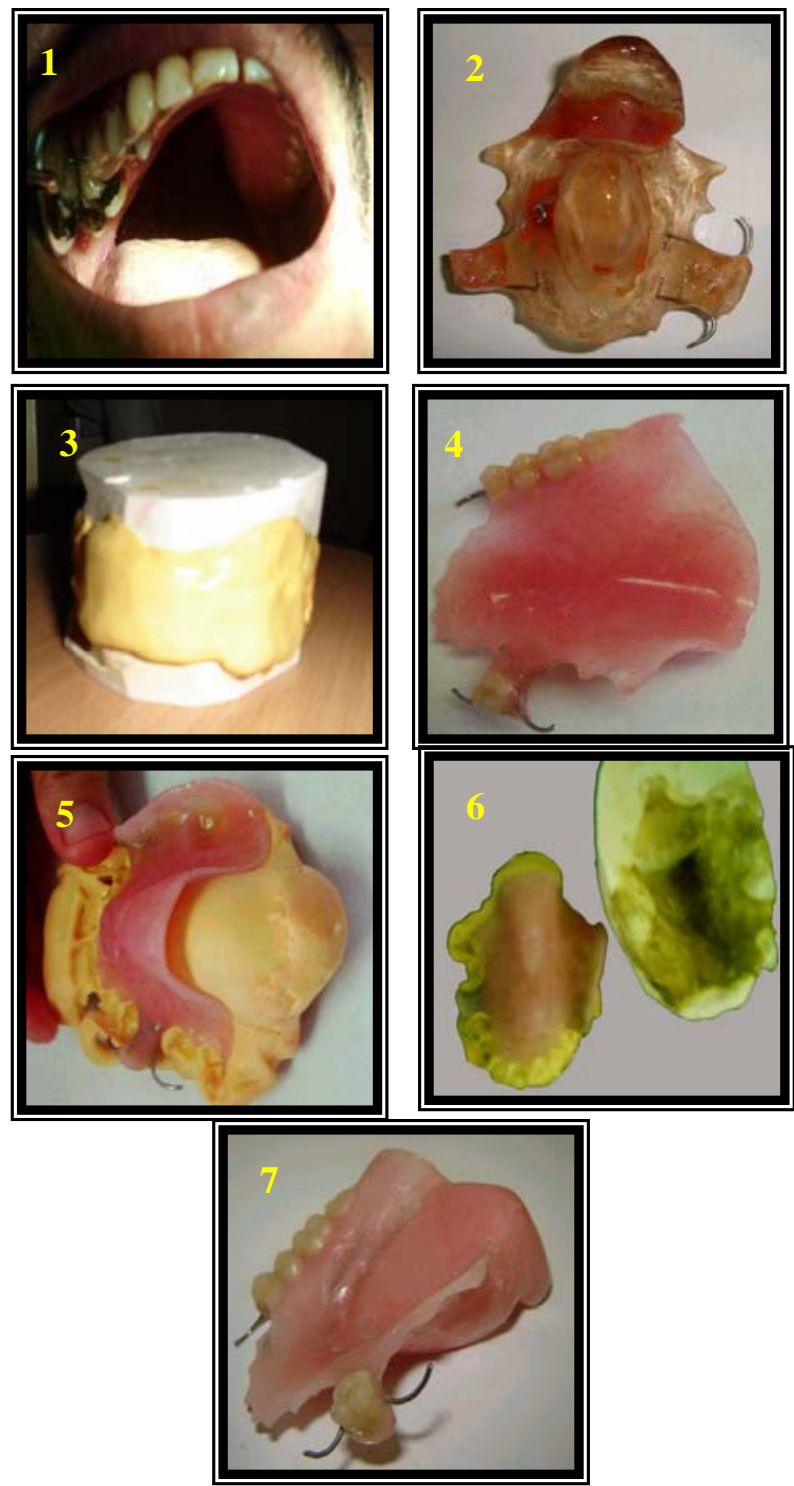

Figure (1) Steps of Maxillofacial obturator construction for patient with gag reflex. 
16. The wax, and the denture were removed from the mouth, the seal was opened, and the wax was polished, packed, and cured (replaced by the hot cure) [Figure 2(No.1)].

17. The acrylic piece which was solid after finishing and polishing, was hollowed by drilling through it using acrylic bur [Figure 2(No.2)], this served to limit the weight of the prosthesis ${ }^{(23,24)}$.

18. The hollow acrylic piece was seated, and permanently sealed to the denture by self cure acrylic resin, and checked [Figure 2(No.3,4)].

19. Maximum retention was provided by clasping the remaining natural teeth (25) [Figure 2(No.5)].

20. Instructions were given to the patient on delivery [Figure 2(No.6)] regarding good
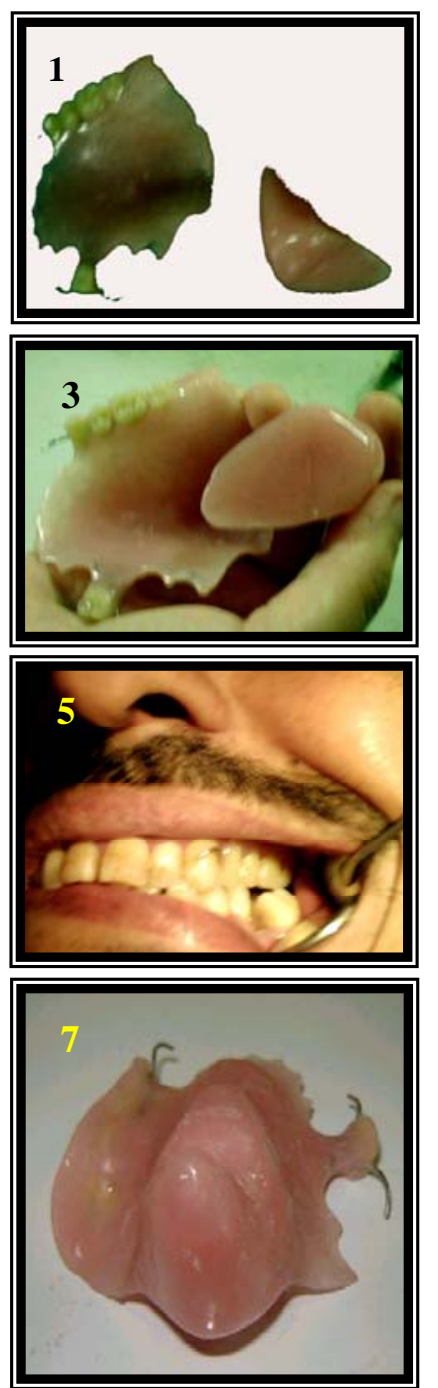

Figure (2) Steps of Maxillofacial obturator construction for patient with gag reflex(Second

Part).
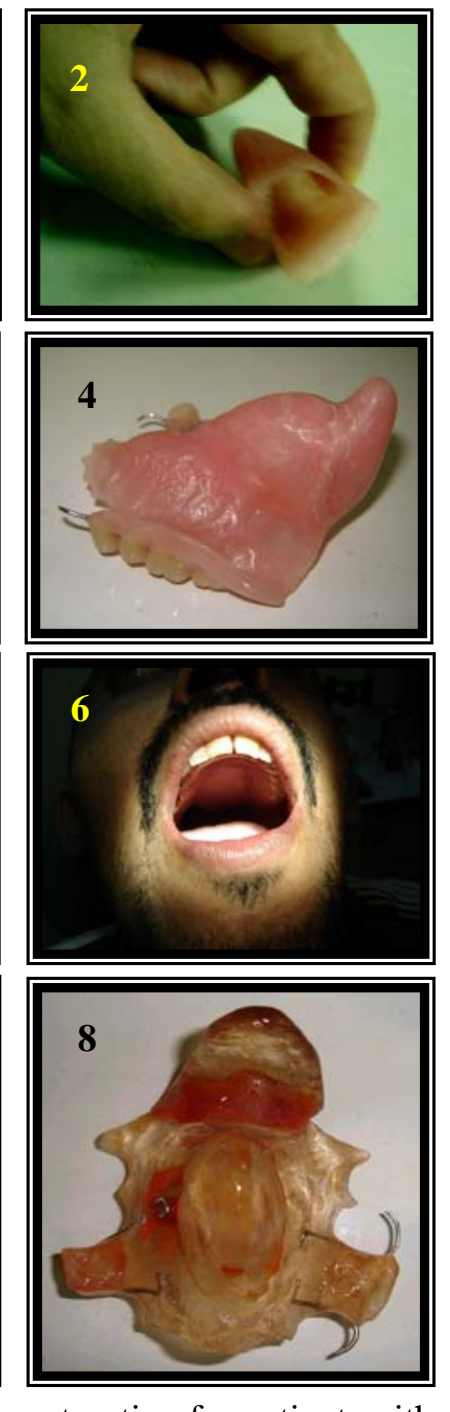

oral hygiene, and proper cleaning of the prosthesis ${ }^{(26)}$.

The part filling the defect in the resulting prosthesis [Figure 2(No.7)] was much larger than the part filling the defect of the previous prosthesis [Figure 2(No.8)], yet, the new prosthesis was still light in weight, and much more comfortable than the old one, also the speech was more intelligible with the new prosthesis.

Adjustments: The first adjustment was done one week after the delivery to check the occlusion by articulating paper, slight relief on the buccal flanges of the left side was made. The second adjustment was done after 3 weeks and included slight adaptation of the clasps with more relief of the buccal flange of the left side. 


\section{DISCUSSION}

The gagging problem was the issue for the study for many authors from long time ago till now. This problem gains a special attention in prosthodontic field as it complicates the task of impression taking, and may even prevent the patient from wearing his prosthesis. Many instructions to lessen the gag problems in prosthetic patient should be considered, and the causes that may contribute to the aggravation of the problem should be looked for, and avoided

In this study, a certain method of impression taking had been used which coincides, to a certain degree, with many old authors opinions $(17,18,19,20,21,22)$ as well as taking advantage of the improvement in the impression materials, and techniques that took advance in the recent years, the impression taking was followed by the construction of a prosthesis which would fill the defect as perfect as possible, restore the missing tissues, and the contour of the palate, as well as being so comfortable to lessen its being noticed by the patient.

The old techniques which were used to solve the problem of this patient depended on constructing a solid obturator which will unnecessarily add additional weight to the prosthesis, the old impression technique and material did not blend perfectly with the cut edges of the defect so it was either too short, which led to a space problem allowing saliva, and other fluids seeping in, and out of the defect, also making a bad reproduction of the patients original voice, or it was too long injuring, and causing bleeding as well as discomfort, and gagging problem during function .

The technique presented in this study used silicone rubber base impression material (Zhermack ,Italy) in impression taking and gave a very good results in preventing the problem mentioned earlier, this impression technique combined with the use of neutral zone principle, ${ }^{(27)}$ and the construction of a hollow obturator, gave the patient a pretty comfortable obturator, and served to eliminate, or decrease the gag reflex problem.

\section{CONCLUSIONS}

The development in the prosthodontic knowledge combined with the advances in the dental materials, as well as the selection of the most suitable old techniques, and ideas can serve to give the patient a very comfortable prosthesis.

\section{REFERENCES}

1. Academy of Prosthodontics, The glossary of prosthodontic terms. $J$ Prosthet Dent,2005; 94 (1): 40.

2. Newton AV The psychosomatic component in Prosthodontics. J Prosthet Dent,1984; 52: 871 -874.

3. Fiske J, Dickinson C The role of acupuncture in controlling the gag reflex using a review of ten cases. $\mathrm{Br}$ Dent J,2001; 190 (11): 611 - 613.

4. Heartwell CM, Rahn AO Syllabus of Complete Denture. $2^{\text {nd }}$ Ed.; Lea and Febiger, Philadelphia,1980; Pp: 403.

5. Bray JJ, Gragg PA, Macknight AD, Mills RG, Taylor DW Lecture Notes on Human Physiology, $3^{\text {rd }}$ ed., Blackwell Scientific Publication,1994; Pp: 566.

6. Guyton C, Hall J Text Book of Medical Physiology. $9^{\text {th }}$ Ed.; W.B Saunders Company,1996; Pp: 849 - 850.

7. Bassi GS, Humphris GM, Longman Lp The etiology and management of gagging: A review of the literature. $J$ Prosthet Dent,2004; 7 (2): 14-17.

8. Haring JI, Jansen L Dental Radiography Principles and Technique. $2^{\text {nd }}$ Ed.; Saunders Imprint of Elsvier,2000; Pp: 399.

9. Vachiramon A, Wang WC Acupressure technique to control gag reflex during maxillary impression procedures. $J$ Prosthet Dent,2002; 88 (2): 236.

10. Robb ND, Crothers AJ Sedation in dentistry: management of the gagging 
patient. Post Graduate Dentist J,1997; 7 (2): 14 -

11. Farmer JB, Connelly ME Palate less dentures: help for gagging patient. $J$ Prosthet Dent,1984; 52(5): 692.

12. Reddick GH Gagging: a chair side approach to control. Br Dent J,1986; 161: $174-176$.

13. Callison GM A modified edentulous maxillary custom tray to help prevent gagging. J Prosthet Dent,1989; 62: 4850.

14. Stewart KL, Rudd KD, Kuebker WA Clinical Removable Partial Prosthodontics. C.V Mosby Company,1983; Pp: 529.

15. Fleece L, Linton P, Dudley B Rapid elimination of a hyperactive gag reflex. J Prosthet Dent,1988; 60 (4): 415.

16. Bill JL Dental appliance for patients with a high gag reflex for the use of dental practitioner. Dental lab J,2006; 31 (5): 54-7.

17. Basker RM, Davenport JC, Tomlin HR Prosthetic Treatment of the Edentulous Patient. $2^{\text {nd }}$ Ed.; Macmillan Education Ltd.,1983; Pp: 222.

18. Shifman A, Finkelstein Y, Nachmani A, Ophir D Speech aid prosthesis for neurogenic velopharangeal incompetence. $J$ Prosthet Dent,2000; 83: 99 - 106.

19. Posti JJ, Näkki K, Siirilä HS Effect of Preimpression Mouth Rinsing on Vis- cosity of Saliva - The Year Book of Dentistry. Year Book Medical Publishers,1978; Pp: 339.

20. Smith C, Crowther C, Willson K, Hothman N, Pharm B, McMillan V, Nursing B A randomized controlled trail of ginger to treat nausea and vomiting in pregnancy. Obstetric and Gynecology,2004; 103: 639 - 645.

21. Ansari IH Management for maxillary removable partial denture patients who gag. J Prosthet Dent,1994; 72: 448.

22. Fenn HR, Liddelow KP, Gimson AP Clinical Dental Prosthetics. $2^{\text {nd }}$ Ed.; Staples Press; London,1961; Pp: 640.

23. . Zarb GA, Bolender CL, Carlsson GE Boucher's Prosthodontic Treatment for Edentulous Patients. 11 ${ }^{\text {th }}$ Ed.; Mosby Inc,1997; Pp: 81.

24. O’Sullivan M, Hansen N, Cornion RJ, Cagna DR The hollow maxillary complete denture: a modified technique. $J$ Prosthet Dent,2004; 91: 591 - 594.

25. Winkler S Essentials of Complete Denture Prosthodontic. W.B Saunders Company,1979; Pp: 121.

26. Alan BC, McGivney GP, Brown DT McCracken's Removable Partial Prosthodontics. $11^{\text {th }}$ Ed.; Elsevier Mosby,2005; Pp: 403-405.

27. Beresin VE, Schiesser FJ The neutral zone in complete dentures. $J$ Prosthet Dent,2006; 95: 93-101. 